\title{
Corticosteroid therapy for IBD: Old and new
}

GR GReEnBERG. Corticosteroid therapy for IBD: Old and new. Can J Gastroenterol 1993;7(2):127-131. Corticosteroids remain the most effective treatment for the management of patients with acute inflammatory bowel disease (IBD). The superior efficacy of corticosteroids has been demonstrated when administered topically for distal ulcerative colitis or systemically for pancolitis, and for active Crohn's disease of the small bowel alone or when combined with colonic disease. Notwithstanding the symptomatic benefit of prednisone in active Crohn's disease, however, only a minority of patients achieve endoscopic remission. Corticosteroids have a broad range of anti-inflammatory effects, including reductions of interleukin-I production by macrophages and interleukin-II synthesis by lymphocytes, inhibition of platelet-activating factor and decreased margination of neutrophils. At pharmacological doses, corticosteroids also induce the synthesis of lipomodulin which, in turn, blocks phospholipase $\mathrm{A}_{2}$ and so limits availability of arachidonate for the production of leukotrienes and prostaglandins. Because corticosteroid treatment is associated with significant side effects, new agents have been sought to achieve equivalent efficacy but with a lower adverse event profile. This approach is predicated on structural changes to the basic hydrocortisone molecule to achieve potent topical anti-inflammatory effects, sufficient water and lipid solubility that allows dissolution within the intestinal lumen and rapid high-first pass metabolism by the liver to products with little or no biologic activity. Three steroid preparations developed for rectal administration include tixocortal pivalate, beclomethasone and budesonide. Controlled trials undertaken in patients with active distal ulcerative colitis indicate each of these products has equivalent or superior efficacy when compared with hydrocortisone and without reductions of serum cortisol. Two preparations, fluticasone and budesonide, have been developed for oral administration and preliminary studies suggest efficacy for both drugs in patients with active ileal Crohn's disease. The first pass corticosteroids are potentially promising new therapeutic agents for the management of IBD.

Key Words: Beclomethasone dipropionate, Budesonide, Fluticasone propionate, Tixocortol pivalate

\section{Bilan de la corticothérapie appliquée à la maladie inflammatoire de l'intestin}

RÉSUMÉ: Les corticostéroïdes demeurent le traitement le plus efficace chez les patients atteints de maladie inflammatoire aiguë de l'intestin. L'efficacité supérieure des corticostéroïdes a été démontrée lors d'administration topique dans la colite ulcéreuse distale ou systémique dans la pancolite, ou dans les cas

Division of Gastroenterology, Mount Sinai Hospital, Department of Medicine, University of Coronto, Toronto, Ontario

Correspondence and reprints: Dr GR Greenberg, Mount Sinai Hospital, 445-600 University Avenue, Toronto, Ontario M5G 1 X5
$\mathrm{B}$ ECAUSE THE ETIOLOGY OF INFLAMmatory bowel disease (IBD) remains unknown, the major objective of drug therapy is to optimize quality of life by suppressing the symptoms of inflammation, without introducing major side effects. Although the therapeutic armamentarium for the management of patients with acute ulcerative colitis and Crohn's disease has expanded considerably over the last decade, corticosteroids continue to be the most effective treatment. The frequent side effects associated with the use of corticosteroids has, however, prompted the development of a new group of agents that may provide certain advantages over currently available steroids by achieving equivalent or superior efficacy with a lower adverse event profile.

\section{EFFICACY OF CONVENTIONAL CORTICOSTEROIDS}

Ulcerative colitis: In acute ulcerative colitis, the value of systemic corticosteroids was demonstrated by Truelove and Witts (1) in a controlled trial comparing oral cortisone against placebo. Subsequently Lennard-Jones et al (2) confirmed the superior efficacy of prednisone over sulphasalazine and placebo in achieving clinical remission. To remain asymptomatic, occasional patients with chronic relapsing ulcerative colitis may benefit from alternate day steroids (3), but neither cortisone nor prednisolone has been shown to be effective for the maintenance of remission when compared to placebo (4).

The intrarectal administration of 
de maladie de Crohn évolutive au niveau du petit intestin seule ou avec atteinte colique. Malgré les avantages de la prednisone pour les symptômes dans la maladie de Crohn active, cependant, seulement une minorité de patients connaîtront une rémission à l'endoscopie. Les corticostéroïdes ont un large spectre d'effets anti-inflammatoires, y compris la réduction de la production d'interleukine-1 par les macrophages et de la synthèse de l'interleukine-2 par les lymphocytes, l'inhibition du facteur d'activation des plaquettes et la diminution de la margination des neutrophiles. $\grave{A}$ des doses pharmacologiques, les corticostéroïdes induisent également la synthèse de lipomoduline qui en retour inhibe la phospholipase A2 pour limiter la disponibilité d'arachidonate dans la production de leucotriènes et de prostaglandines. Parce ce que le traitement aux corticostéroïdes est associé avec des effets secondaires importants, de nouveaux agents ont été étudiés pour obtenir une efficacité équivalente avec un profil d'effets secondaires plus discret. Cette approche se base sur des changements structurels de la molécule d'hydrocortisone de base afin de parvenir à des effets anti-inflammatoires topiques puissants, une solubilité dans l'eau et les lipides suffisante pour permettre une dissolution dans la lumière de l'intestin et un métabolisme de premier passage rapide et intense au niveau du foie qui donnerait des produits exerçant une activité biologique faible, voire nulle. Le pivalate tixocortal, la béclométhasone et le budésonide sont trois préparations stéroïdes mises au point pour administration rectale. Des essais contrôlés entrepris auprès de patients porteurs de colite ulcéreuse distale active indiquent que chacun de ces produits possède une efficacité supérieure ou équivalente à celle de l'hydrocortisone, sans réduire le cortisol sérique. Deux préparations, la fluticasone et le budésonide, ont été mises au point pour administration orale et les études préliminaires suggèrent qu'elles sont efficaces chez les patients porteurs d'une maladie de Crohn iléale active. Les corticostéroïdes de premier passage sont de nouveaux agents thérapeutiques potentiellement prometteurs pour le traitement de la maladie inflammatoire de l'intestin.

hydrocortisone is effective treatment for patients with acute distal ulcerative colitis $(5,6)$. Although absorption of corticosteroids after topical administration is less than after oral administration, prolonged treatment with steroid enemas also may produce adrenal suppression (7). Moreover, compared with topical hydrocortisone, 5-ASA enemas show equivalent or superior efficacy for achieving remission in acute proctosigmoiditis (8). Thus 5-ASA enemas may be the initial treatment of choice when disease is limited to the distal colon. Of the 10 to $20 \%$ of proctosigmoiditis patients who are unresponsive to 5-ASA enemas, the addition of topical steroids may induce a remission in some cases.

Crohn's disease: The superior efficacy of prednisolone for patients with Crohn's disease of the small bowel alone, or when combined with colonic involvement was established by the $\mathrm{Na}$ tional Cooperative Crohn's Disease Study (NCCS) (9), and similar results were obtained in the European Crohn's Cooperative Study (10). In contrast to the NCCS, the European trial also showed that prednisolone was effective for colonic Crohn's disease and further indicated that once remission had been achieved for either ileal or colonic disease, a low dose of steroids may have benefit in maintaining remission for up to two years. Indeed, to maintain clinical remission after administration of steroid therapy in Crohn's disease, up to two-thirds of patients may become steroid-dependent. Both studies $(9,10)$ demonstrated that in patients with quiescent disease the prophylactic use of steroids is of no benefit in preventing recurrence. Notwithstanding the benefit of prednisolone for achieving clinical remission in active Crohn's disease, only a minority $(29 \%)$ of patients also achieve endoscopic remission (11). The administration of sulphasalazine, in addition to prednisone, for patients with active Crohn's disease causes a more rapid initial improvement, but after 16 weeks' therapy sulphasalazine plus prednisone is not significantly better than prednisolone alone for the control of symptoms related to inflammation (12).

\section{MECHANISMS OF ACTION}

Corticosteroids have a broad range of effects in IBD that include suppres. sion of the inflammatory response and alteration of certain immunologically mediated events. Both the early manifestations of inflammation, in cluding increased vascular permeability, vasodilatation and infiltra. tion of neutrophils, as well as the late manifestations such as vascular proliferation, fibroblast activation and collagen deposition are suppressed by corticosteroids (13). Steroids influence monocyte, lymphocyte and neutrophil populations. Circulating lymphocytes and monocytes decline after steroid ad. ministration, which is caused by redistribution from the circulation to the lymphoid tissue. Steroids also reduce interleukin-II synthesis by lymphocytes, reduce interleukin-I produc. tion by macrophages and inhibit production of platelet-activating fac. tor. Corticosteroids suppress bacteri. cidal activity by reducing macrophage and monocyte $\mathrm{IgG}$ and $\mathrm{C}_{3} \mathrm{~b}$ receptor expression. On the other hand, cir culating neutrophils are increased after steroid administration due to enhanced release from bone marrow and decreased adherence of neutrophils t inflamed tissues.

In vitro studies indicate that pred nisolone blocks the synthesis lipooxygenase and cyclooxygenase products by inducing the synthesis of lipo modulin. It has been proposed tha lipomodulin, in turn, reduces phospho lipase- $A_{2}$ production, thereby limitin the availability of arachidonate for the synthesis of leukotriene $\mathrm{B}_{4}$ (a lipo oxygenase product), prostaglanding and thromboxane $A_{2}$ (products of the cyclooxygenase pathway). Whether corticosteroids have a similar effect it IBD patients is less clear. In a recent study, administration of long-term prednisolone did not alter mucosal phospholipase $A_{2}$ activity in the neoterminal ileum of patients with recurrent active Crohn's disease (14) the unaffected phospholipase $\mathrm{A}_{2} \mathrm{ac}$ tivity in the mucosal biopsies was as sociated with the presence of active inflammation at endoscopy. Cortico. steroids also enhance absorption 
water and electrolytes from the gut and improve nutrient intake by stimulating appetite.

Although all of these actions by steroids could potentially contribute to the suppression of inflammation and provide symptomatic relief, it remains uncertain which of these mechanisms predominate in achieving improved clinical outcome for patients with IBD. Inhibition of neutrophil and monocyte migration into inflamed intestinal tissue has been suggested as the most important factor contributing to the therapeutic efficacy of corticosteroids in IBD (13). Perhaps most noteworthy is that elucidation of various mechanisms whereby corticosteroids act has provided little insight into the basic etiology of IBD.

\section{IDEAL STRUCTURE-ACTIVITY PROFILE FOR CORTICOSTEROIDS}

Treatment with conventional corticosteroids is associated with significant side effects. In the NCCS, prednisolone administered for 17 weeks caused major adverse events in over $50 \%$ of patients, including 'moon face', acne, ecchymosis and hypertension (15). A $30 \%$ incidence of osteoporosis has also been reported in patients receiving corticosteroids for IBD (16). Risk factors include severe small intestinal disease, intestinal resection and premature menopause, as well as high dose steroid therapy. Osteonecrosis has been reported in $4.3 \%$ of patients treated with corticosteroids for IBD over a 10 . year period (17). Because administration of conventional corticosteroids is associated with a significant adverse event profile, several avenues have been sought to achieve equivalent efficacy with a lower incidence of side effects. Whether the concomitant administration of 5-ASA products (12), other immunosuppressive agents (18), certain antibiotics or the addition of nutritional therapy (19), will achieve this objective requires clarification. An alternate approach to treatment of patients with IBD is predicated on changes to the basic hydrocortisone molecular structure to achieve a more optimal structure-activity profile.
Compared with hydrocortisone, this ideal structure-activity profile includes three major characteristics. First, there should be relatively selective glucocorticoid activity with very potent topical anti-inflammatory effects. A double bond in the A-ring between positions 1 and 2 increases the affinity for the glucocorticoid but not the mineralocorticoid receptor, while an oxygen function at position 11 in the $\mathrm{C}$-ring is required for glucocorticoid receptor binding. Enhanced topical anti-inflammatory potency can be achieved by the introduction of lipophilic constituents into the $17 \alpha$ and/or the $16 \alpha$ or $17 \alpha$ positions of the corticosteroid D-ring; esterification in the $17 \alpha$ position markedly enhances glucocorticoid activity (20).

Second, when administered orally or rectally there should be relative stability with sufficient water and lipid solubility to allow dissolution, as well as effective absorption into the gut wall. Conventional corticosteroids such as prednisolone are rapidly absorbed from the gastrointestinal tract, and up to $80 \%$ of the drug becomes systemically bioavailable. In active small intestinal Crohn's disease the absorption of prednisolone may be delayed but the total amount absorbed is unchanged (21). Thus, the third characteristic is that once absorbed there should be rapid metabolism of the steroid to products with little or no biologic activity. As the liver is the major site for steroid metabolism, this breakdown is referred to as high-first pass hepatic metabolism, which can be achieved by esterification at the 21 position of the D-ring.

\section{NEWER CORTICOSTEROIDS}

Several new preparations have been developed that begin to approach this optimal structure-activity profile for corticosteroids. Three preparations developed for rectal administration include tixicortal pivalate, beclomethasone and budesonide, while two preparations, fluticasone and budesonide have been developed for oral administration.

Tixocortal pivalate: This synthetic steroid is a derivative of hydrocortisone where the 21-hydroxyl group on the D-ring is replaced by a 21 -thiol group esterified with pivalinic acid. This change in structure conveys high-first pass metabolism, but does not enhance glucocorticoid receptor affinity or potency when compared to hydrocortisone (22). The efficacy of tixocortal pivalate in patients with left-sided ulcerative colitis has been studied in three controlled trials in the United States comprising 337 patients where three weeks' administration of $250 \mathrm{mg}$ tixocortal pivalate enemas were compared to $100 \mathrm{mg}$ hydrocortisone enemas (23). Clinical improvement was observed in $68 \%$ of patients after tixocortal pivalate and $75 \%$ after hydrocortisone, without serum cortisol reductions in either group. A dose response study of $250 \mathrm{mg}, 500 \mathrm{mg}$ and $1000 \mathrm{mg}$ tixicortal pivalate enemas did not, however, demonstrate any improved efficacy at the higher doses. Notwithstanding the absence of steroid side effects, the low topical potency of this agent and the absence of superior efficacy over hydrocortisone suggests that tixocortal pivalate will have a limited role as a topical agent for left-sided ulcerative colitis and is unlikely to be of value as an oral agent for the treatment of more extensive ulcerative colitis or Crohn's disease.

Beclomethasone dipropionate: This is a $17 \alpha$ substituted glucocorticoid with a topical potency about 80 -fold greater than hydrocortisone, which is inactivated by hepatic first pass metabolism. Randomized, double-blind trials have assessed the effect of $0.5 \mathrm{mg}$ betamethasone dipropionate enemas when compared with $5 \mathrm{mg}$ beclomethasone phosphate in patients with distal ulcerative colitis (24-26). The overall therapeutic response was equivalent in the two treatment groups. Suppression of adrenocortical function was found in the majority of patients receiving betamethasone phosphate but did not occur in any of the patients receiving beclomethasone dipropionate. The bioavailability of beclomethasone dipropionate when administered rectally or orally in humans has not been studied.

Fluticasone propionate: This is a $17 \alpha$ 
propionate with an S-fluoromethyl carbothioate side chain in the $17 \beta$ position. The topical potency of this new steroid is about 200 -fold greater than hydrocortisone, and the altered ring structure conveys biotransformation in the liver to metabolites of low glucocorticoid potency (20). Oral bioavailability of fluticasone is very low, likely reflecting not only hepatic first pass metabolism, but also poor absorption from the gastrointestinal tract because of low solubility. When given in a single oral dose to patients with a well-established ileostomy, $72.7 \%$ of the drug was recovered in the ileostomy effluent (27). Oral fluticasone $20 \mathrm{mg} /$ day has been studied in 12 patients with mild to moderately active Crohn's disease. After three weeks treatment, fluticasone caused a significant fall in the Crohn's disease activity index (CDAI) from $193 \pm 84$ to $122 \pm 51$ and improved ${ }^{111}$ In leucocyte scan images in seven patients, without changes in plasma cortisol (28). Fluticasone $20 \mathrm{mg} /$ day has also been administered to 12 patients with untreated celiac disease (29). After six weeks of treatment, a mean 2 $\mathrm{kg}$ weight gain, a rise in albumin, improvement in the lactulose/mannitol excretion ratio and improved histology was reported. Two of the patients in this latter study (29) had suppressed cortisol values to synacthen after the six weeks of therapy. Oral fluticasone is not, however, effective treatment for active distal ulcerative colitis. A double-blind

\section{REFERENCES}

1. Truelove SC, Witts LJ. Cortisone in ulcerative colitis. Final report on a therapeutic trial. $\mathrm{Br}$ Med J 1955; ii:104-8.

2. Lennard-Jones JE, Longmore AJ, Newell AC, et al. An assessment of prednisone, salazopyrine and topical hydrocortisone hemisuccinate used as outpatient treatment for ulcerative colitis. Gut 1960;1:217-27.

3. Powell-Tuck J, Brown RL, Chambers TJ, Lennard-Jones JE. A controlled trial of alternate day prednisolone as a maintenance treatment for ulcerative colitis in remission. Digestion 1981;22:263-70.

4. Lennard-Jones JE, Misiewicz JJ, Connell AM, et al. Prednisone as maintenance treatment for ulcerative randomized trial comparing 30 patients who received fluticasone $20 \mathrm{mg} /$ day versus 29 patients who received placebo found similar clinical, sigmoidoscopic and histologic responses in the two groups (27).

Budesonide: This is a nonhalogenated glucocorticoid which is structurally related to $16 \alpha$-hydroxyprednisolone. This drug is a 1:1 mixture of two epimers designated $22 \mathrm{R}$ and $22 \mathrm{~S}$ with the $22 \mathrm{R}$ epimer about three times more potent than the $22 \mathrm{~S}$ epimer (20). Budesonide has a topical potency about 200-fold greater than hydrocortisone, a water solubility that is approximately 100 times higher than fluticasone and undergoes hepatic first pass metabolism into metabolites with low glucocorticoid effects. A multicentre randomized trial comparing budesonide $2 \mathrm{mg} / 100$ $\mathrm{mL}$ enemas with prednisolone disodium phosphate $31.25 \mathrm{mg} / 100 \mathrm{~mL}$ enemas administered for four weeks in 64 patients with active distal ulcerative colitis indicated $52 \%$ healing in patients receiving budesonide versus $24 \%$ healing in patients receiving prednisolone enemas (30). Patients receiving prednisolone enemas, but not budesonide enemas, had a significant depression of endogenous cortisol levels during the treatment period. Further recent multicentre trials undertaken in patients with left-sided ulcerative colitis demonstrated that budesonide enemas were comparable for achieving remission compared with methylpred-

colitis. Gut 1960;1:217-27.

5. Truelove SC. Treatment of ulcerative colitis with local hydrocortisone hemisuccinate sodium. A report on a controlled therapeutic trial $\mathrm{Br}$ Med J 1958;ii:1072-7.

6. Watkinson G. Treatment of ulcerative colitis with topical hydrocortisone sodium. A controlled trial employing restricted sequential analysis. Br Med J 1958;ii:1077-82.

7. Cann PA, Holdsworth CD. Systemic absorption from hydrocortisone foam enemas in ulcerative colitis. Lancet 1987;i:922-3.

8. Sutherland LR, Martin F, Guer S, et al. 5. Aminosalicylic acid enema in the treatment of distal ulcerative colitis, proctosigmoiditis and proctitis. Gastroenterology 1987;92:1894-8.

9. Summers RW, Switz DM, Sessions JT, nisolone $20 \mathrm{mg} / 100 \mathrm{~mL}$ enemas (31), and to 5 -ASA $4 \mathrm{~g} / 160 \mathrm{~mL}$ enemas (32), without causing adrenal suppression. Budesonide $0.5 \mathrm{mg}$ suppositories given three times daily have also been reported to be effective in the symptomatic treatment of patients with pouchitis, causing a reduction in leukotriene $\mathrm{B}_{4}$ and prostaglandin $\mathrm{E}_{2}$ levels in fecal dialysates (33); however, $60 \%$ of patients relapsed within eight weeks of stopping therapy. Three preliminary reports (34-36) have ap. peared on the efficacy of a slow release oral preparation of budesonide $9 \mathrm{mg} /$ day administered to patients with active Crohn's disease. The composite results comprising 47 patients indicated a significant reduction of $\mathrm{CDAl}$, without changes in serum cortisol levels or side effects. Multicentre randomized trials comparing oral budesonide against placebo and against prednisone in patients with active Crohn's disease are currently in progress.

\section{SUMMARY}

The development of new glucocor. ticoids characterized by high topical anti-inflammatory activity and first pass hepatic metabolism represent potentially promising new approach to the management of patients with IBD. Whether long-term administration of these agents will maintain symptomatic improvement without systemic or local side effects requires careful prospective evaluation.

et al. National Cooperative Crohn's disease study: Results of drug treatment. Gastroenterology 1979;77:847-69.

10. Malchow H, Ewe K, Brandes JW, et al European Cooperative Crohn's Disease Study ECCDS): Results of drug treatment. Gastroenterology 1984;86:249-66.

11. Modigliani R, Mary JY, Simon JF, et al. Clinical, biological and endoscopic picture of attacks of Crohn's disease. Gastroenterology 1990;98:811-8.

12. Rijk MCM, Ruud A, van Hogezand RA, et al. Sulphasalazine and prednisone compared with sulphasalazine for treating active Crohn's disease. Ann Intern Med 1991;114:445-50.

13. Stenson WF. Action of anti-inflammatory drugs. In: Bayless 
TM, ed. Current Management of Inflammatory Bowel Disease; BC Decher Inc Toronto 1989;46-50.

14. Olaison G, Sjodahl R, Tagesson C. Glucocorticoid treatment in ileal Crohn's disease: relief of symptoms but not of endoscopically viewed inflammation. Gut 1990;31:325-8.

15. Singleton JW, Law DH, Kelly ML, Jr, Mekhjiaan HS, Sturdevant RAL. National Co-operative Crohn's disease study: adverse reactions to study drugs. Gastroenterology 1979;77:870-82.

16. Compston JE, Judd D, Crowley EO, et al. Osteoporosis in patients with inflammatory bowel disease. Gut 1987;28:410-5.

17. Vaidl N, Sparberg M. Steroid-related osteoporosis in inflammatory bowel disease. Gastroenterology 1989;96:62-7.

18. O'Donoghue DP, Dawson AM, Powell-Tuck J, et al. Double-blind withdrawal trial of azothioprine as maintenance treatment for Crohn's disease. Lancet 1978;ii:955-7.

19. Sitzmann JV, Converse RL Jr, Bayless TM. Favorable response to parenteral nutrition and medical therapy in Crohn's colitis. A report of 38 patients comparing severe Crohn's and ulcerative colitis. Gastroenterology 1990;99:1647-52.

10. Brattsand R. Overview of newer glucocorticosteroid preparation for inflammatory bowel disease. Can J Gastroenterol 1990;4:407-14.

1. Shaffer JA, Williams SE, Turnberg LA, et al. Absorption of prednisolone in patients with Crohn's disease, Gut 1983;24:182-6.

12. Lorochelle P, Du Souich P, Bolte E, Lelorier J, Goyer R. Tixocortol pivalate, a corticosteroid with no systemic glucocorticoid effect after oral, intrarectal, and intranasal application. Clin Pharmacol Ther 1983;33:343-50.

23. Hanauer SB, Kirsner JB, Barrett WE. The treatment of left-sided ulcerative colitis with tixocortol pivalate (TP). Gastroenterology 1986;90:A1449. (Abst)

24. Bansky G, Buhler H, Stanun B, et al. Treatment of distal ulcerative colitis with beclomethasone enemas: high therapeutic efficacy without endocrine side effects. A prospective, randomized, double-blind trial. Dis Col Rect 1987;30:288-92.

25. Kumana CR, Meghii M, Seaton T, Castelli M. Beclomethasone dipropionate enemas for treating inflammatory bowel disease without producing Cushing's syndrome or hypothalamic pituitary adrenal suppression. Lancet 1982;I:579-83.

26. Van der Heide $H$, van den Brandt-Gradel V, Tytgat GNJ, et al. Comparison of beclomethasone dipropionate and prednisolone 21-phosphate enemas in the treatment of ulcerative proctitis. J Clin Gastroenterol 1988;10:169-72.

27. Angus P, Snook JA, Reid M, Jewell DP. Oral fluticasone propionate in active distal ulcerative colitis. Gut 1992;33:711-4.

28. Carpani de Kasld M, Peters AM, Lavender JP, Hodgson HJF. Fluticasone propionate in Crohn's disease. Gut 1991;32:657-61.

29. Mitchison HC, AI Mardini H, Gillespie S et al. A pilot study of fluticasone propionate in untreated coeliac disease. Gut 1991;32:260-5.

30. Danielsson A, Hellers G, Lyrenas E, et al. A controlled randomized trial of budesonide versus prednisolone retention enemas in active distal ulcerative colitis. Scan J Gastroenterol 1987;22:987-92.

31. Bianchi Porro G, Campieri M, Bianchi $\mathrm{P}$, et al. Comparative trial of budesonide and methylprednisolone enemas in the treatment of ulcerative colitis. Gastroenterology 1992;102:A595. (Abst)

32. Lamers C, Meijer J, Engels L, et al. Comparative study of the topically acting glucocordcosteroid budesonide and 5 -aminosalicylic acid enema therapy of proctitis and proctosigmoiditis. Gastroenterology 1991;100:A223. (Abst)

33. Belluzzi A, Campieri M, Miglioli M, et al. Evaluation of flogistic pattern in 'pouchitis' before and after the treatment with budesonide suppositoties. Gastroenterology 1992:102:A593. (Abst)

34. Wolman SL, Greenberg GR. Oral budesonide in active Crohn's disease: an initial experience. Gastroenterology 1991;100:A263. (Abst)

35. Lofberg R, Danielsson A, Salde L. Oral budesonide in active ileocecal Crohn's disease - a pilot trial with a topically acting steroid. Gastroenterology 1991;100:A226. (Abst)

36. Roth M, Ueberschaer B, Ewe Y, et al. Oral slow release budesonide induces remission in active Crohn's disease with little effect on adrenal function. Gastroenterology 1992;102:A688. (Abst) 


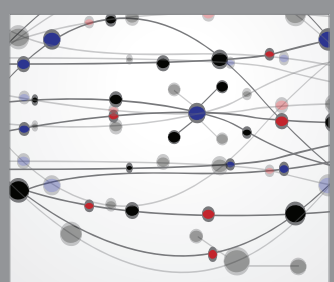

The Scientific World Journal
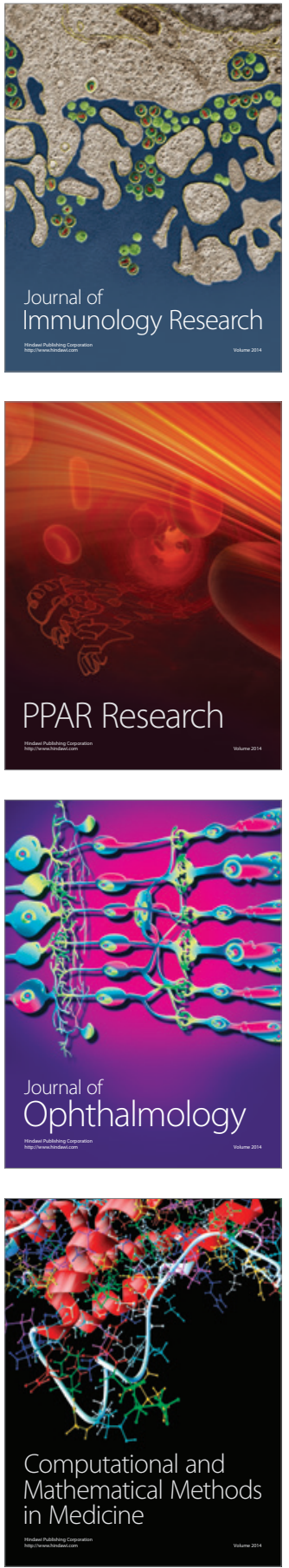

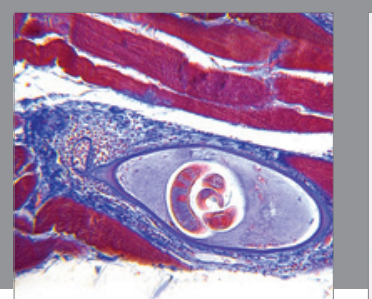

Gastroenterology Research and Practice

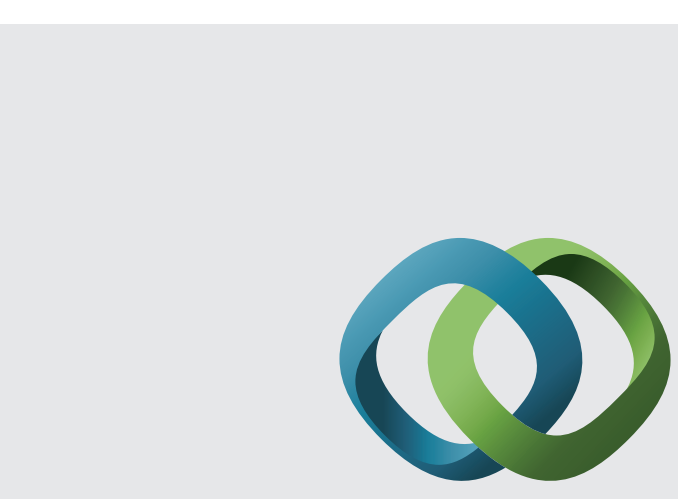

\section{Hindawi}

Submit your manuscripts at

http://www.hindawi.com
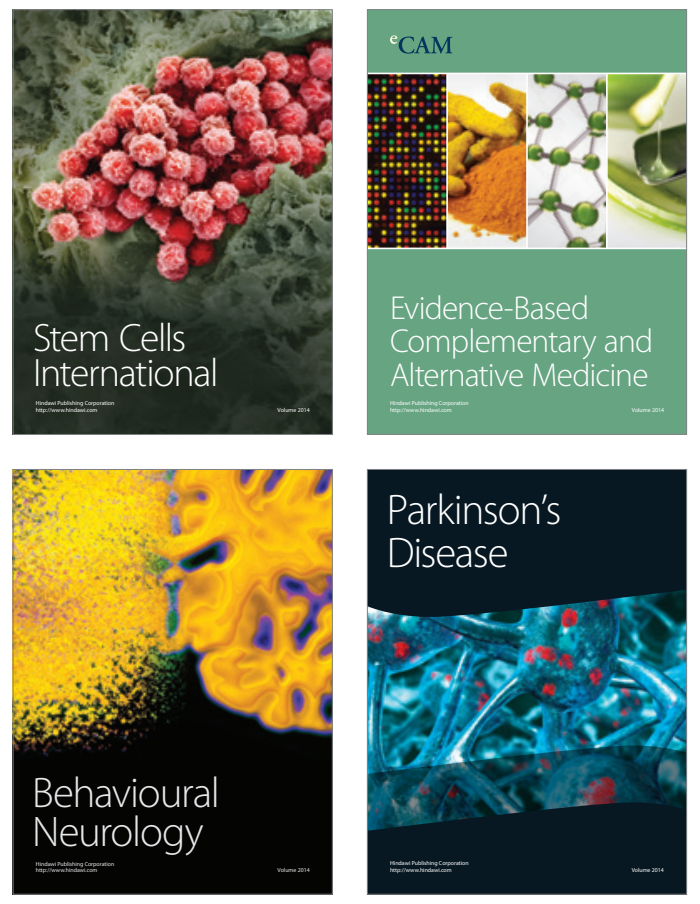
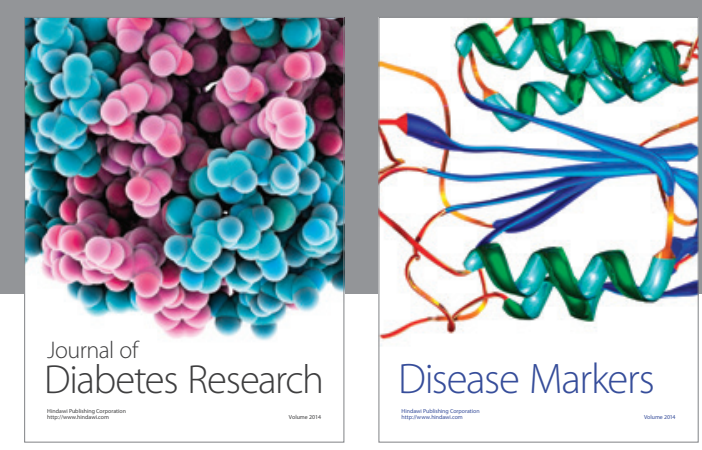

Disease Markers
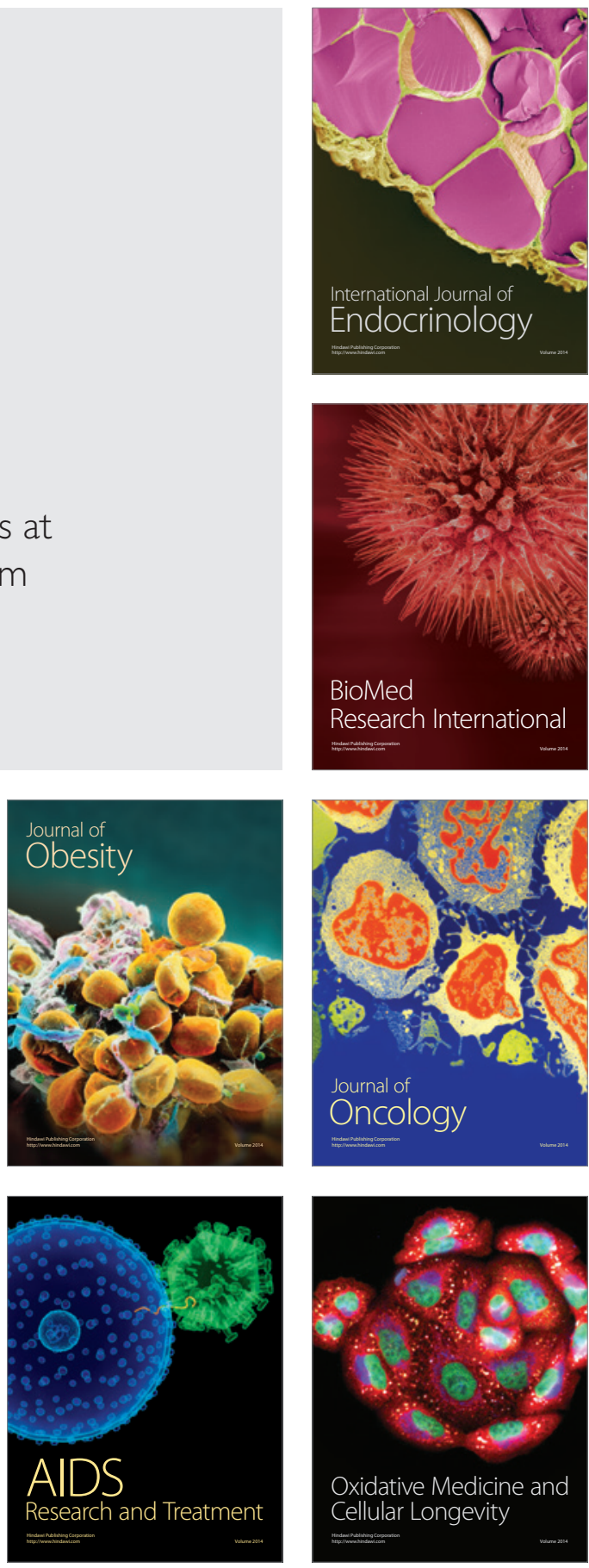